\title{
'A place to be (me)': a qualitative study on an alternative approach to treatment for persons with dual diagnosis
}

\section{Clara De Ruysscher, Stijn Vanheule \& Stijn Vandevelde}

To cite this article: Clara De Ruysscher, Stijn Vanheule \& Stijn Vandevelde (2017): 'A place to be (me)': a qualitative study on an alternative approach to treatment for persons with dual diagnosis, Drugs: Education, Prevention and Policy, DOI: 10.1080/09687637.2017.1375461

To link to this article: http://dx.doi.org/10.1080/09687637.2017.1375461

曲 Published online: 21 Sep 2017.

Submit your article to this journal $\pi$

LII Article views: 7

Q View related articles $\widetilde{ }$

View Crossmark data $\nearrow$ 


\title{
'A place to be (me)': a qualitative study on an alternative approach to treatment for persons with dual diagnosis
}

\author{
Clara De Ruysscher ${ }^{\mathrm{a}}$, Stijn Vanheule ${ }^{\mathrm{b}}$ and Stijn Vandevelde ${ }^{\mathrm{a}}$ \\ ${ }^{\mathrm{a} D}$ Department of Special Needs Education, Ghent University, Ghent, Belgium; ${ }^{\mathrm{b}}$ Department of Psychoanalysis and Clinical Consulting, Ghent \\ University, Ghent, Belgium
}

\begin{abstract}
Objectives: This study aims at gaining insight into an alternative approach to treatment for persons with dual diagnosis by unraveling the daily practice of Villa Voortman, a community-based meeting place in Ghent (Belgium) offering support to this group.

Methods: Twelve in-depth interviews were conducted with several actors: visitors, staff members, volunteers, and persons involved from outside the meeting place.

Results: First, Villa Voortman was experienced as 'a place to be', providing visitors a possibility to feel safe and accepted, and belong to a peer group. Voluntary participation to activities is crucial to install such feeling. In time, the meeting place also becomes 'the place to be', as visitors start to feel at home. Secondly, it functions as 'a place to be me', helping participants to (re-)build their identity and become visible citizens.

Conclusions: The findings are highly consistent with recovery literature and Lacanian ideas on the treatment of psychosis. Some 'contours' that shape the daily practice of Villa Voortman could be identified: particularizing to personal needs, having a focus on personal, social, and structural aspects of recovery and the coexistence of different discourses.
\end{abstract}

ARTICLE HISTORY

Received 3 July 2017

Revised 7 August 2017

Accepted 31 August 2017

\section{KEYWORDS}

Co-morbidity/dual diagnosis; treatment; qualitative research; recovery

\section{Introduction}

Persons with dual diagnosis, that is the comorbidity of a substance use disorder and a psychiatric disorder (e.g. psychosis), are often characterized by a variety of complex needs. In addition to addiction and mental health problems, they frequently face judicial problems, housing problems, poverty, a poor physical health, and social isolation, among other things (Drake et al., 2001; Ness, Borg, \& Davidson, 2014). As a consequence, the treatment of persons with dual diagnosis is experienced as challenging by many professionals working in mental health care and addiction treatment settings. Today, an integrated and multidimensional treatment approach is increasingly considered to be more adequate than a parallel or sequential treatment approach, although scientific evidence remains weak (Drake \& Wallach, 2000; Murthy \& Chand, 2012). In such integrated programs, the focus is placed on both substance use problems and psychiatric problems, in order to meet the complex needs of persons with dual diagnosis (Horsfall, Cleary, Hunt, \& Walter, 2009). Additionally, in line with recent trends in both mental health care and addiction policy, the emphasis of these integrated programs is increasingly shifting from symptom reduction and cure towards supporting personal recovery processes and stabilization of persons with dual diagnosis (Anthony, 1993; Cruce, Öjehagen, \& Nordström, 2012; Davidson \& White, 2007; Drake et al., 2001; Gagne, White, \& Anthony, 2007), moving away from deficit-oriented approaches.

These recent developments towards integrated stabilization- and recovery-oriented treatment for persons with dual diagnosis led to a wide variety of treatment modalities, ranging from specialized therapeutic communities and pharmacological treatment over case management to harm reduction and self-help groups (Drake et al., 2001; Horsfall et al., 2009). However, recent literature shows that there remain several barriers to treatment for persons with dual diagnosis, related to both personal characteristics of the patients (e.g. low motivation for treatment, cultural beliefs, [self-]stigma) and structural factors (e.g. exclusion from specialized treatment services, excessive waiting lists, organizational, and financial aspects of treatment) (Le Boutillier, Slade, et al., 2015; Priester et al., 2016). Such barriers contribute to high dropout rates, an overly narrow focus on symptom reduction and lack of attention for the social context in integrated treatment services for persons with dual diagnosis (Drake et al., 2001; Farkas, 2007; Le Boutillier, Chevalier, et al., 2015; Slade, Amering, \& Oades, 2008).

In order to tackle these challenges, it could be helpful to look at innovative practices that manage to engage with this often 'hard-to-reach' group. An example of such a practice was developed in Ghent (Belgium): Villa Voortman. This community-based meeting place aims to offer 'a welcoming place' for persons with dual diagnosis (comorbidity of psychosis and substance use) who often lost connection to other more traditional psychiatric and social care settings (Vandevelde et al., 2015). The central aim of Villa Voortman is to enable 'human encounters' as a starting point for empowering visitors (as they are called) to find a valued place in 
society. Therefore, a minimal structure is provided in which only two rules apply: physical/verbal violence and drug use (or being under influence) are not tolerated at the meeting place. Its daily practice is underpinned by a horizontal organizational structure, inspired by democratic drug-free therapeutic community principles and Rapoport's (1957) principles of permissiveness and communalism (Broekaert, Vandevelde, Soyez, Yates, \& Slater, 2006; Rapoport \& Rapoport, 1957; Vandevelde \& Broekaert, 2009; Vandevelde et al., 2015). Visitors come on a voluntary basis and are free to take part in a wide range of activities, such as poetry writing, sculpting, painting, philosophy, and cooking. The daily practice and artistic projects of Villa Voortman are funded by the psychiatric hospital from which it was founded, the city council and a not-for-profit association (called 'friends of Villa Voortman'). A more detailed description of Villa Voortman can be consulted in Vandevelde et al. (2015).

The meeting place offers an alternative to spending time on the street or in residential psychiatric settings, thus countering social isolation and medicalization. The experience and tacit knowledge built in practices such as Villa Voortman could play a vital role in recognizing how support for persons with dual diagnosis can best take shape (Kirmayer, 2012; O'sullivan, 2005). Indeed, Stanhope and Solomon (2008) argue that, in order to gain better understanding of the ways personal recovery processes can be supported through treatment, research should focus on micro-level practices and processes rather than aiming to measure generalizable outcomes (Leamy, Bird, Le Boutillier, Williams, \& Slade, 2011). In particular, they refer to qualitative research methods that give a central position to the lived experiences of the persons involved in the practices under study (Stanhope \& Solomon, 2008). Also Pilgrim (2009) argues for the use of practicebased, context-close, and ethnographic research methods in order to get close to the personal meanings and experiences of the participants (Pilgrim, 2009). Therefore, the aim of this study is to gain insight into an alternative community-based approach to treatment for persons with dual diagnosis, by unraveling the daily practice of Villa Voortman from an idiographic qualitative perspective.

\section{Methods}

\section{Methodological approach}

In order to focus on idiographic perspectives of treating dual diagnosis, an explorative qualitative study was conducted (Baxter \& Jack, 2008). Data were collected using in-depth interviews and analyzed by means of thematic analysis (Clarke \& Braun, 2014). In order to focus on micro-processes, each case was analyzed in detail before searching for patterns and themes across cases (Flood, 2010; Smith, Flowers, \& Larkin, 2009).

\section{Research location and participants}

The study took place in Villa Voortman, a community-based meeting center in Ghent (Belgium). Characteristically, most of the visitors, as they are called, of Villa Voortman are excluded from society on several levels. Their persistent psychotic symptoms and substance use problems, together with financial, judicial, and housing problems often cause visitors to live on the street or spend a lot of their time alone, isolated from community life. Moreover, they often lost connection to regular treatment after a series of unsuccessful admissions and bad experiences: their substance use problems are believed to be too severe to fit into psychiatric treatment and vice versa. On a daily basis, an average of 25-35 clients visit Villa Voortman, staying for a few hours or a full day. Besides staff members (psychologist, psychiatrist, social workers), there are also volunteers and interns around supporting the daily practice.

In order to obtain rich information on the functioning of Villa Voortman, and to do justice to its complexity, triangulated participant perspectives were obtained by recruiting 12 participants from four groups of actors: three visitors (i.e. persons with dual diagnosis), three staff members (one psychologist, one psychiatrist, one creative therapist), three volunteers, and three people who are involved from outside the meeting center. The visitors were purposefully selected based on the fact that they are senior regular visitors. In the selection process of the other participants, we aimed at obtaining a wide diversity of perspectives and backgrounds. The volunteers had different professional backgrounds. The group of persons involved from outside the meeting place consisted of one street corner worker, one artist with a studio in the building where Villa Voortman houses, and one judicial actor who helped to establish a good working relationship between the prison of Ghent and Villa Voortman. All participants were considered to be good informants because of their extensive experience with Villa Voortman. Table 1 gives an overview of participant characteristics.

\section{Procedure}

All participants were personally invited by the first author for an in-depth interview covering their personal viewpoints about the daily practice of Villa Voortman. More precisely, they were asked about what it is that makes activities work (or not) for the visitors; about the kind of social relating taking place; about key values and working principles; and about the role that the meeting place plays in their lives. The interviews took place in a quiet room at Villa Voortman, except for one that took place in a local café. Interviews lasted between 40 and $120 \mathrm{~min}$, were audio-recorded and transcribed verbatim by the first author. Additionally, during the entire period of the research project (May-October 2016), the first author conducted a participant observation at Villa Voortman for approximately one day per week. The researcher recorded thoughts and reflections in a research diary.

\section{Data analysis}

First, an individual idiographic analysis was conducted for each interview. After transcribing the interview, the first author read it multiple times to get immersed into the data, while writing down thematic descriptive comments. Based on 
Table 1. Participant characteristics.

\begin{tabular}{llllc} 
Name & Sex & Age & Role at Villa Voortman & $\begin{array}{c}\text { Amount of years active at/connected } \\
\text { to Villa Voortman (years) }\end{array}$ \\
\hline Nick & $\mathrm{M}$ & {$[41-50]$} & Visitor & 5 \\
James & $\mathrm{M}$ & {$[51-60]$} & Visitor & 5 \\
Amanda & $\mathrm{F}$ & {$[51-60]$} & Visitor & 3 \\
Chris & $\mathrm{M}$ & {$[51-60]$} & Psychologist & 5 \\
Adam & $\mathrm{M}$ & {$[41-50]$} & Psychiatrist & 5 \\
Rob & $\mathrm{M}$ & {$[41-50]$} & Creative therapist & $1 / 2$ \\
Katie & $\mathrm{F}$ & {$[51-60]$} & Volunteer & 4 \\
Hannah & $\mathrm{F}$ & {$[51-60]$} & Volunteer & 2 \\
Fay & $\mathrm{F}$ & {$[21-30]$} & Volunteer & 2 \\
Jim & $\mathrm{M}$ & {$[31-40]$} & Artist & 5 \\
Andy & $\mathrm{M}$ & {$[61-70]$} & Judicial actor & 4 \\
Caroline & $\mathrm{F}$ & Street corner worker & 3 \\
\hline
\end{tabular}

Table 2. Overview and occurrence of themes.

\begin{tabular}{|c|c|c|c|c|c|c|}
\hline & & \multicolumn{5}{|c|}{ Occurrence of themes per participant group } \\
\hline & & Visitors (3) & Staff members (3) & Volunteers (3) & Persons involved from outside (3) & Total (12) \\
\hline \multirow{9}{*}{ Themes } & Villa Voortman as a/the place to be & & & & & \\
\hline & Feeling safe & 3 & 3 & 3 & 3 & 12 \\
\hline & The predominance of the peer group & 2 & 2 & 3 & 2 & 9 \\
\hline & Feeling accepted & 3 & 3 & 3 & 3 & 12 \\
\hline & Feeling at home & 3 & 3 & 2 & 2 & 10 \\
\hline & Voluntary basis & 2 & 2 & 2 & 3 & 9 \\
\hline & Villa Voortman as a place to be me & & & & & \\
\hline & (Re-)building one's identity & 2 & 3 & 2 & 2 & 9 \\
\hline & Becoming a visible citizen & 2 & 2 & 3 & 3 & 10 \\
\hline
\end{tabular}

these exploratory notes she drew up a schedule of emergent themes and links between the themes. In the second phase, the schedules of the individual interviews were gradually integrated in a scheme in order to identify superordinate themes and dynamics. During this phase, participant observation data became intertwined with the interview data.

In order to deal with subjectivity, and to increase the inter-rater reliability of the results, the first author and the coauthors met at several moments during the analysis process. The analysis of the first interview was carried out by all authors. In the second phase, we selected four interviews, based on their richness and the diversity of topics covered. These were discussed extensively and integrated into the scheme with superordinate themes and dynamics. After the first author completed the entire analysis, the co-authors independently scrutinized one additional randomly selected interview and verified to what extent their analysis related to the themes identified by the first author. They concluded that the overall results fit the information from the additional interviews.

\section{Ethical considerations}

Ethical approval was granted by the Ethics Committee of Ghent University Hospital (EC UZG 2016/0530). Written informed consents were obtained from all participants. In order to guarantee anonymity, names of participants are altered.

\section{Results}

Participants' experiences can be clustered around two main themes: on the one hand Villa Voortman functions as 'a place to $b e^{\prime}$, and even starts functioning as 'the place to be'; and on the other hand it functions as 'a place to be $m e^{\text {'. }}$

Most visitors of Villa Voortman are confronted with exclusion from society on several levels; they are 'invisible' citizens, who lost 'their' place in society. Villa Voortman, by contrast, offers a safe hub where they feel welcomed and accepted. In that sense, the meeting place functions as a place to be. Gradually, visitors even start to feel 'at home' at the meeting place, as becomes apparent in daily routines: visitors gather in the living room to drink coffee and chat, and have lunch together. In that sense, the function of Villa Voortman makes a transition from being a place to be, that is a safe haven, to being the place to be, that is a homely place that the visitors have made their own.

At the same time, Villa Voortman is a vibrant place where artistic and creative activities and projects are continuously taking place. These activities are organized on a voluntary basis, and start from visitors' personal interests, as well as from personal interests of volunteers and staff. By cultivating these interests, visitors find a (new) way to express themselves and gradually build up a new sense of identity. In doing so, senior visitors inspire new visitors, who might primarily come to Villa Voortman to find some peace of mind. In that way, the meeting place is experienced as a place to be $m e$, that is a place where visitors are encouraged and even expected (in balance with their own capacities) to go through a processes of transition: by engaging in valued activities they start cultivating positive identities, thus taking a distance from (self-)stigmatizing labels. Importantly, these activities and projects provide an important link to the outside world.

Table 2 provides an overview of the themes and subthemes detected across the interviews. Also, it shows the 
number of participants talking about these themes, per participant group.

Table 2 shows that all themes are well represented in the accounts of the participants. However, some of the themes were discussed in more positive or negative ways depending on the participant group. In the description of the results, these ambiguities will be further explored and made explicit.

\section{From 'a place to be' to 'the place to be'}

When asked about the important elements of Villa Voortman, most participants described the meeting place as welcoming. Different factors contribute to this welcoming climate: feeling safe, feeling accepted, feeling 'at home', organizing all activities on a voluntary basis, and treating each other as equals. Chris, the psychologist, refers to the primary function of Villa Voortman as 'creating an asylum', that is, a safe place where people feel protected and at ease. In what follows, the experiences of the participants regarding each aspect of the meeting place as $a /$ the place to be are described in detail.

\section{Feeling safe}

All participants expressed the importance of feeling safe. This sense of safety is twofold: Villa Voortman provides a safe haven away from threatening aspects of the visitors' outside world (e.g. homelessness, judicial problems) and the restlessness of their inner world (e.g. psychosis, drug craving, loneliness). Nick, a visitor, describes this as follows:

\footnotetext{
A lot of people, me too sometimes, find more rest here than at home. So at home they can't sleep, then they come here, they lie down on the sofa and fall asleep. Because it is calm, because it feels safe.
}

The importance of having a safe haven also becomes apparent in the story of Amanda, a visitor who spends a lot of time in 'the crowdedness of the streets', as she calls it, where she is often confronted with bullying others. For her, knowing that the outside world cannot simply come in, for example because every visitor needs to have an intake conversation before being allowed to Villa Voortman, contributes to her sense of security. Indeed, Villa Voortman is her hideaway from the tumult of the streets:

When I need to leave the Villa at the end of the day, back into that rotten world, it already starts on the tram... Crowdy, full. Students. It is totally different. When I come from here and have to go back into the mass. Into that buzz. You can't imagine how much I suffer from that.

Adam, the psychiatrist of Villa Voortman, added another dimension to this theme. Most visitors lost connection to treatment after a long and difficult trajectory within regular psychiatric services. In order to offer them a real break, Villa Voortman aims to be a safe haven, not only away from street life, but also away from the pressure of psychiatric and social services:

You are safe in the sense that you won't be asked certain questions, that you can trust that they won't be asked. And safe for the chase of psychiatric services or judicial authorities who try to correct you. So that... That no unexpected things will happen when you are here. And that's when you feel at home. [...] The outside world can come in, but the outside world has to obey to the rules of the house. A sort of code, almost like a code of conduct.

Another aspect of safety is related to the inner world of the visitors, as most of them suffer from both psychosis and substance use problems. Villa Voortman counters these threatening aspects of their inner world, in different ways. For example, while keeping away from moral judgments about illicit drugs, there is a clear rule that all drug-use is forbidden within the meeting place. As a consequence, visitors experience a sense of safety: they know that being in the meeting place keeps them away from the compulsion to use drugs for a few hours. Frequently, psychotic experiences too trigger a severe sense of inner restlessness. On the one hand visitors are allowed to speak about psychotic experiences, on the other hand Villa Voortman aims at providing a protective buffer by actively setting boundaries. Fay, a volunteer, expresses this as follows:

When there are people suffering from acute psychosis or schizophrenia, yeah then it isn't always useful to talk to them loads. Sometimes you need to take control, in order to avoid it getting out of hand for them.

However, sometimes finding a good balance between, on the one hand, accepting psychotic idiosyncrasies and visitors' drug-related activities outside the meeting place, and, on the other hand, providing a buffer against excessive problems is difficult, as the sense of safety is also subject to interactions between the visitors. For example, when visitors encourage each other to use drugs, this might impose a threat to that sense of security. This becomes apparent as Andy, a judicial actor, expresses his concerns regarding Vicky, a former mentally ill offender who visits Villa Voortman on a regular basis:

Sometimes Vicky has moments that she doesn't want to go to the Villa because she thinks there is too much drug use, or... Even if she doesn't use in the Villa herself... but because the visitors are still using it. And offer her stuff, or ... I don't know. That is a problem too. How can you keep that under control without being repressive?

Andy's concern indicates that Villa Voortman as 'a place to be' is also fragile, since the sense of safety is constantly subject to detrimental group dynamics too.

\section{Feeling accepted}

Another aspect that contributes to the welcoming climate is for its visitors to feel accepted. All staff members and volunteers expressed the importance of accepting visitors as they are, rather than having the reflex to 'cure' or improve them. For instance, Katie, a volunteer, clearly put this forward as the most important aspect of Villa Voortman:

It is just the acceptance. That you come in and it is OK, you are OK. Not like "we will change this and that and we will make you better", no, there is no... There is no recovery policy here or a vision to strive for recovery. This is a meeting place and by accident recovery can occur. But it is not the aim. And that creates an enormous sense of security. As soon as you enter, you get a kiss and the question "welcome, how are you?" instead of "did you use drugs yesterday?" or "are you gonna use again tomorrow?" or "it would be better if you didn't use". 
This is also expressed by Nick and James, who described that, in contrast to other psychiatric settings, in Villa Voortman you get the freedom to 'bluntly' be yourself without being judged for it:

Visitors are often rebellious here, and that is tolerated by the staff. In most other settings you need to behave. [...] I find that the most important thing here is tolerance. [...] Also from staff towards patients. Visitors can be brutal towards staff members sometimes. And in psychiatry that is not allowed. Or way way way less. (Nick)

No matter how extreme it is, your thoughts or your way of thinking, you can say it here. And I couldn't do that at all in psychiatry. By doing that, I have violated many crusted established values there (in psychiatry). (James)

\section{The predominance of the peer group}

Several participants discussed how in Villa Voortman, everyone treats each other as equals. For many visitors, this contrasts with previous experiences in traditional hierarchically structured psychiatric settings. In society too, visitors often find themselves in unequal power relationships, and are addressed from a dominant position (e.g. by police, judicial actors). In Villa Voortman, however, the group is structured horizontally and everyone (both visitors, staff, and volunteers) is part of this group: the peer group predominates and power inequalities are minimized. For example, this is reflected in the way that everyone greets each other, that is in a cordial way with a kiss and a hug. Equality is also reflected in weekly 'visitors meeting', where the visitors themselves plan the activities of the next weeks. Adam, the psychiatrist of Villa Voortman, links this horizontal structure to recent trends in mental health care:

It is a different movement, one in which patients can truly speak up, one in which caregivers can truly speak up. Both as caregivers and humans. And it shouldn't be the organizations or the financial means that determine the rules. [...] Everyone has the right to speak up, both the users of the system and the ones organizing the system. And that's what also happens here.

According to Hannah, a volunteer, one reason why such horizontal structure can be maintained is because Villa Voortman does not actively take up medical tasks. She explains that unavoidably, the prescription and distribution of medication (e.g. antipsychotics, methadone) installs a power imbalance between 'staff' and 'patients', and therefore better takes place in services outside Villa Voortman:

I think, if you'd get your medication here, you'd feel more like a patient. I think we'd also have to be like "did you take your medication?" and thus play a different role. It is not just them (the visitors) who feel more like patients. We'd also play a different role and position ourselves above them and tell them what to do. So I wouldn't like that.

However, despite the predominance of the peer group, several participants indicate that in practice, there are still hierarchical differences between visitors, staff members, and volunteers. This is illustrated in the story of Katie, one of the volunteers, as she explains her own position:

As a volunteer you have a position, imagine... Even if I wouldn't cook here, I feel like the cook [of a summer camp]. You get to hear different things. Because you are not... I think that we, even though in theory there is no ranking and power and order, are experienced as different. [...] And volunteers don't have their own agenda, zero point zero, unlike the interns and staff members. But I don't know if they think about it a lot, but they do experience a difference.

Also, Caroline, a street corner worker who regularly visits Villa Voortman, recalled feeling surprised and disappointed when some visitors told her that she could never fully be 'one of them':

I was seen as a staff member, and the volunteers were too. Whilst... Yeah, of course, I'm not a visitor, of course I'm different and look differently at things. [...] But no matter how open you are, you can't be one of them. And that doesn't mean they (the visitors) don't like you, but you are different. [...] In the evening, you go home to your own house. You close the door whilst you know some visitors will have to sleep rough.

Remarkably, the horizontal structure at Villa Voortman is not explicitly discussed by the visitors themselves. Moreover, they even appear to prefer a certain level of hierarchy. For example, Amanda mentioned that she would prefer the staff to install a drug test at the entrance, in order to make sure nobody enters under influence. Nick, in his turn, indicated that he prefers to have patient files in order to keep track of the visitor's treatment trajectory.

\section{Feeling 'at home'}

All participants talked about the 'warmth' that creates a feeling of being 'at home': Villa Voortman is not only a place to be, that is a safe shelter, but also the place to be for visitors. One aspect that contributes to this feeling of homeliness is the fact that Villa Voortman is located in an old and almost worn-down house with many rooms, decorations, a grand staircase, and a big private garden. Fay explains that this sense of 'faded glory' creates a relaxed and chaotic atmosphere that gives visitors freedom to find their place within Villa Voortman:

The house has little corners and things to do everywhere, which gives people the option to hide for a little while, and actually they are free to do what they want, and I think that's what appeals to people. Also with having psychosis and addiction problems, you can't ask for too much. And... There is always a bit of chaos that ... sometimes causes problems but I think that is why most people like it here.

This sense of homeliness is also clearly present in the experiences of Amanda. As she was giving a detailed description of the house, she attached a lot of importance to the status and grandeur of the building. A few months after the interview with her, Villa Voortman would move to a new location. This caused a lot of distress, as she was afraid that the new location would not have the same outlook:

Why do you think people love to come here? When you enter you see these wooden stairs. When it is cleaned, it is so pretty. And all the marble around it. [...] You really are in a villa. [...] Now we move to those barracks. They are nothing compared to this. Such ghetto, such poverty. Are you still gonna call it Villa Voortman? [...] Bungalow Voortman, that's what you can call it.

Another important aspect that contributes to feeling at home is the fact that a hot lunch is prepared and served 
every day. Fay explains how this daily routine provides structure and predictability:

It may sound really silly, but I find it important, the eating together, doing the dishes together. I find it important because it ... Yeah, the homeliness, it provides a solid ground, the normal reference ... How to say ... Reference points, things to hold on to.

\section{Voluntary basis}

In Villa Voortman everything is organized on a voluntary basis: there are no mandatory therapeutic sessions, visitors are free to come and go as they wish, and take part in the activities they want. However, voluntariness does not imply that nothing is demanded; visitors are expected to take responsibility for their own actions and choices. This became visible in the story of Nick, as he was comparing residential psychiatric treatment to Villa Voortman. In a residential treatment program, he felt like he was not expected to do much since all control was taken out of his hands. In Villa Voortman this is different:

You can be more yourself, yeah, that's true. But the trick at Villa Voortman is to make use of it, to really see it as an opportunity for yourself as a visitor. So "what can I do with the Villa?" rather than "what is the Villa going to do for me?". Do you understand? Like drumming and taking part in the workshops.

Thus, visitors themselves are made responsible for their own acts and activities. This requires a different attitude of the staff, as Rob, a staff member, explains:

From the moment that something goes wrong in a hospital, they will intervene and try to correct it and... Whilst here, there is more of a "wait and see" attitude... For example Bert (visitor), he is not well, everyone can see that he is not well, and everyone makes a careful attempt to get closer to Bert. But if Bert says "leave me alone", yeah, then we'll listen to that and the team will wait rather than saying "okay, we have to arrange an involuntary admission to the hospital".

However, at certain moments, voluntariness comes under pressure. For example, when visitors do not respect house rules (i.e. no drug use or violence inside the meeting place) or refuse to engage in any activities, staff members sometimes feel frustrated and are tempted to take more control and make certain activities obligatory (e.g. the weekly visitors meeting). Psychologist Chris claimed that it is important to resist this temptation:

When you take over, then actually what you are saying is "they cannot do it, we have to take control". And then you are going away from the empowerment idea. [...] I think, when you create more rules or become stricter, it is out of a kind of overpowering, a sort of fear that it will go wrong.

At the same time, visitors indicate that sometimes it would be desirable for staff to take initiative and be more proactive with regard to the needs of the visitors. For example, according to Nick, the meeting place does not play an active enough role in 'caring' for its visitors:

But the staff isn't really proactive here. It is not like they ... It is not like they have a big plan to help people. Not enough, if you ask me. I would do a bit more. And have patient files and all that But they don't want that. So they only work in a reactive way. Only... They mainly are reactive to situations. [...] Actually, the question is "who is taking care of me?" That is the question. They don't do that here. They don't take care of you here. And that is exactly what they do in psychiatry. A lot more than here.

\section{Villa Voortman as 'a place to be me'}

The fact that visitors feel welcome, safe and accepted forms the breeding ground for subsequent creative processes taking place at Villa Voortman. More specifically, visitors usually start engaging in activities such as making music, painting, cooking, bike repairing... These activities express and cultivate own interests and talents, thus giving visitors a medium and language to start dialoguing with others. In that respect, Villa Voortman helps in establishing a personal identity, and is experienced as a place to be me, that is a place where social processes take place, and where a safe sense of self gets established. In particular, two processes stand out: (re-)building one's identity through self-expression and becoming a visible citizen.

\section{(Re-)building one's identity through self-expression}

At Villa Voortman, visitors are encouraged to express themselves by finding a medium through which they start conversations with others. The many creative activities organized at Villa Voortman are main facilitators of these identity-building processes. Rob, a staff member, explained that creative activities bring the interests and talents of visitors to the foreground:

I think that most creative activities actually allow for visitors to regain status: "I am the poet", "I am the illustrator", "I am the painter", "I am the artist". And I think that fits well within society.

As a result, visitors stop seeing themselves, and are no longer seen by others as 'patients' or 'persons with dual diagnosis', but as individuals with a unique identity. Jim, an artist with a studio in Villa Voortman, mentioned that these creative processes have a destigmatizing effect, even to the point that it is difficult for outsiders to distinguish staff members from visitors:

The biggest question that people ask at the ... at the like Indian Summer events ... "is that a visitor or do they work here?" And in the end, does it matter? Because he's a musician now, so who cares if he's a visitor or if he works here. And... But the fact that people are asking that question already kind of takes away the stigma a little bit. [...] But it takes time before people are still seen as equals.

In this respect, Adam, the psychiatrist, explained that despite the voluntary basis of these artistic and creative activities, visitors are expected and encouraged to actively elaborate a sense of self. He explained that at the basis of this expectation lies the idea that every person nurtures the desire to 'be someone' and to give shape to this sense of identity by expressing oneself and engaging in dialogue with others. Thus, at Villa Voortman, visitors are encouraged to actively (re-)build their identity, away from old 'spoiled identities' (Smith, Padgett, Choy-Brown, \& Henwood, 2015):

Actually, we ask a lot from our visitors. We don't patronize them, it is not like we put nothing in the way. Actually, we put a lot in 
the way. We insist on being someone here. (...) We say "you have to show yourself", so you have to look yourself in the eyes. That is the consequence. You can only show yourself if you are willing to look at yourself. That is what we expect. So it's not like we don't ask for anything.

Remarkably, however, all three interviewed visitors expressed their frustrations concerning other visitors' lack of engagement in these creative processes. For example, when James was asked why he thinks other visitors come to Villa Voortman, he answered the following:

I think some come for the same reasons as I do, but unfortunately most visitors come here to just spend their day, drink coffee and smoke cigarettes and sit in the sofa all day.

Also Nick, who organizes the philosophy activities, showed his disappointment when talking about other visitors' motivation:

There are a few projects that involve some people, but at the moment many visitors come without doing anything, and I'd like to change that. It has decreased a bit compared to before. I tried to organize a writing workshop, but it didn't work out. They weren't interested.

However, these frustrations are put into a different perspective by Chris, the psychologist, as he described how visitors go through transitions during their time at Villa Voortman. He stressed the importance of maintaining a good balance between the visitors' needs and strengths by fostering different expectations for each visitor, rather than applying a one-size-fits-all approach:

I think we need to individualize more, particularize. And with people who are still very confused or psychotic, you just need to try to build a connection, until something comes, and only then you can expect more. [...] It's the principle of "the strongest links can bear the greatest burdens", I think. If you'd ask everyone to bear the same burden, it just wouldn't be a democracy.

All three interviewed visitors are senior regular visitors. As a consequence, they are expected to play an active role in Villa Voortman. For them, this might seem in contrast to visitors who are not ready to be as active. Also, Hannah, a volunteer, gave a counterweight to their frustrations by pointing out that such individual differences and expectations are inherent to life outside Villa Voortman too:

I don't think we necessarily need to be better than the world around us. You also have... I know quite a lot of people, especially amongst elderly, who don't do much more than have breakfast, watch TV a bit, read the newspaper, take a nap, have a chat with the neighbors. We aren't all as creative. But it needs to be stimulated and we need to be open to it. But on the other hand, we shouldn't judge too fast by saying things like "oh, he isn't doing anything".

\section{Becoming a visible citizen}

A second process coming to the fore when talking about Villa Voortman as a place to be me is becoming a 'visible' citizen in society. Certain participants explicitly talked about the visitors as a group of people who usually remain invisible in society. Chris stresses that they should help visitors in becoming visible citizens:

It is very important that we don't just stay a ghetto here and an alternative psychiatric setting that works in a certain way, but that we also make a link to the outside world. [...] The more interest, the more people talk about Villa Voortman, the more these vulnerable citizens get to be seen. Indeed, many of our visitors are that damaged that we cannot turn them into "good" citizens. But inclusion should be more than just taking them out of psychiatric institutions and dropping them in a meeting place.

In this respect, volunteer Fay explained how social relationships and feeling accepted can provide a boost for visitors to build new connections in the 'outside world':

Because you welcome people here, and they feel included... Cause often it is about people who are excluded, who... From their own circles, and then from psychiatry ... They get kicked out everywhere. And when they can find connection here, they start making links to the outside too. [...] In a city, that is really important.

For example, by taking part in the music activities, Amanda gradually discovered that singing provides her an outlet. She also learned that she loves to perform and started singing at the monthly 'Open Gate' events. This led to the invitation by a theatre company to perform during one of their show tours, which Amanda accepted. Consequently, she started sharing positive stories about her theatre experiences, and along this way served as an example for other visitors.

However, according to some participants such strong link to the outside world has disadvantages too. For example, volunteer Katie explained that she avoids coming to the monthly 'Open Door' afternoon, because it might undermine the feeling of safety:

What I find problematic sometimes is the... The constant showing to the outside world. I think it happens too often and too much sometimes. [...] The focus is on it too much. And what are the disadvantages of that? The security is lost, the safety feeling, and the fact that the same people are in the spotlight and others fall by the wayside. And it brings along a lot of stress.

\section{Discussion}

The aim of this study was to gain insight into an alternative community-based approach to treatment for persons with a dual diagnosis, by means of a qualitative interview study in the Belgian meeting place Villa Voortman. The results show that the meeting place is experienced as 'a place to be' (i.e. a welcoming, safe place where visitors feel accepted), as 'the place to be' (i.e. a second home), and as 'a place to be $\underline{m e}$ (i.e. a place where visitors gain a new sense of identity and become visible citizens in society). These results tally quite well with a number of perspectives that have been articulated in relevant literature.

First, there are remarkable similarities between our results and the way in which the recovery paradigm has been conceptualized and operationalized in mental health care and addiction treatment. For example, in Villa Voortman major importance is attached to creating a safe and homely atmosphere. Together with the horizontal structure between all parties, this encourages open human encounters. Not only do these social relationships create a sense of belonging and connectedness, they also constitute a starting point for visitors to (re-)build a positive sense of identity away from (self-)stigma. Such transitional interpersonal processes 
towards a new identity are seen as vital to recovery (Leamy et al., 2011; Price-Robertson, Obradovic, \& Morgan, 2016). Slade (2012) argues that in order to support personal recovery processes, it is crucial to create opportunities for individuals to discover new ways to express themselves and engage in a dialogue with others: 'hope, without opportunity, dies' (Slade, 2012; Slade, Williams, Bird, Leamy, \& Le Boutillier, 2012, p. 101). At Villa Voortman, this is done by offering a wide range of activities and encouraging the visitors to use these opportunities as they wish. Interestingly, the recoverypromoting activities at Villa Voortman do not start from an explicit model as to what recovery implies for individual visitors. Through its internal dynamics the meeting place implicitly encourages personal recovery. Perhaps internal tensions in the functioning of the meeting place (e.g. disagreement about obligatory participation in activities or not; imposing more explicit rules of conduct or not), which are not always easy to bear, provide a space where individual participants are brought to the point of making a decision about, and taking responsibility for their own life.

Also, despite the fact that Villa Voortman is defined as a 'meeting place', that is a place where human encounters take place, its actual function is mostly defined by the visitors themselves. Visitors are given the freedom to set their own priorities and find support at the meeting place in a way that complies with their own preferences, interests, and needs. This implies that visitors are approached as active agents who set the course for their own recovery process rather than as passive recipients of a predefined therapeutic program, which tallies with ideas in recovery literature (Davidson, Shahar, Lawless, Sells, \& Tondora, 2006; Gagne et al., 2007). At the same time, different expectations are held for each visitor, according to their strengths, needs, and motivation. For example, experienced visitors are expected to play a more active role and take greater responsibility within the daily practice, while new visitors are only expected to feel welcome, explore the meeting place, and build social relationships. Such a case-by-case, particularizing approach fits well with the recovery paradigm, as recovery processes are deemed deeply personal and unique in nature (Anthony, 1993; Leamy et al., 2011). Therefore, applying a one-size-fitsall approach would not meet the needs of the visitors.

The particularizing not pre-programmed approach of Villa Voortman also tallies with Lacanian ideas on the stabilization of psychosis (Leader, 2011; Vanheule, 2011). In line with what psychologist Chris indicates, the Lacanian model suggests that to stabilize psychosis a safe haven is primordial or, as Zenoni suggests, an 'asylum' should be provided. Derived

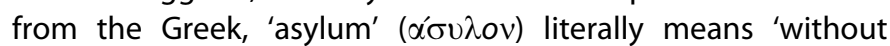
the right of seizure' or 'safe from violence' (http://www.etymonline.com). In analogy with this meaning, the primary function of Villa Voortman thus is to be an inviolable place, that is a place of protection where visitors are allowed to 'simply be', without any further expectations (cf. a place to be). Another Lacanian idea permeating the practice of Villa Voortman is that clinical work is organized along the lines of an 'ethics of lack' (Zenoni, 2009). This means that a priori normative expectations formulated for help-seeking persons are kept minimal, while maximal space is created for individual expression and exploration. The focus is on the particular situation of each patient ('what do they want?') instead of focusing on a therapeutic ideal ('what do we want for them?') (Zenoni, 2009). In this context two characteristics are of key importance: (1) a distance is taken from normalizing goals that aim at 'improving', 'adapting to reality', or 'getting better', and (2) a wide range of possible activities is provided and encouraged (e.g. art, creativity, games, sports, music), such that help-seeking individuals engage in undertakings that support a stable self-experience and secure relations with others (Zenoni, 2009).

Next to supporting the individual stabilization- and recovery-oriented processes in its visitors, Villa Voortman also has a significant structural and social orientation, which adds another component to how they stimulate recovery (Harper \& Speed, 2012). Indeed, several activities such as the monthly 'Open Gate'-afternoons (where the local neighbors come over for coffee and cake) tally with a social approach to recovery, in which full participation and the reclaiming of valued social roles are crucial (Price-Robertson et al., 2016; Tew et al., 2012; Vandekinderen, Roets, Roose, \& Van Hove, 2012). Moreover, these activities put Villa Voortman on the map as an established, visible and well-known meeting place with a positive reputation, known by many citizens of Ghent. By actively pursuing social inclusion and full participation, the meeting place fights the 'invisibility' of its visitors in society, thus counteracting stigma and social inequality.

As already indicated, the results showed that different participants sometimes had diverging and conflicting opinions about aspects of how Villa Voortman functions. A recurrent point of tension lies in the fact that the feeling of safety is continuously subject to group dynamics and interactions. For example, the presence of certain visitors can be experienced as threatening or unfavorable by others, for example out of fear that they will encourage them to keep using drugs. Also, the balance between creating a safe haven and having a strong link to the outside world is often fragile. For example, not all visitors enjoy the public events organized by Villa Voortman because it might disrupt the safety of 'their home'. Also, the balance between the personal agency of the visitors and the sense of responsibility of the staff is fragile. Interestingly, these tensions are not problematized at Villa Voortman. The (apparent) contradictions between different aspects of the daily practice coexist and are not considered as obstacles that need to be resolved, but as issues that need to be discussed, and as tensions that might guide visitors in making own choices.

Overall, the ever-changing group dynamics and particularizing approach to the individual needs of each visitor make it difficult to capture the practice of the meeting place in a set of 'active ingredients'. This is in line with conclusions in the recovery literature that state that providing standardized 'cookbook' guidelines for recovery-oriented treatment of persons with dual diagnosis is impossible: recovery processes are deeply personal in nature and take place in non-linear ways (Khoury \& del Barrio, 2015; Vandekinderen et al., 2012). Instead, it is more meaningful to understand the above-mentioned key aspects (i.e. particularizing, having a focus on both the personal, social, and structural aspects of recovery and 
allowing tensions to exist) as important outlines or 'contours' that shape the meeting place. At the same time, as Villa Voortman mainly engages with a subgroup of clients who have gone through a long treatment trajectory without lasting success, it remains vital to situate the meeting place within a broad policy context and continuum of treatment modalities. The daily practice of Villa Voortman bears witness to an active and ongoing process in which a variety of perspectives can be integrated and that is inherently characterized by dynamics, contradictions, simultaneity, and complementarity (Broekaert, 2009; Broekaert, Van Hove, D'Oosterlinck, \& Bayliss, 2004).

\section{Limitations and future directions}

A first limitation of this study lies in the fact that the three visitors that were part of the participant group can be seen as 'role models', that is experienced visitors who are in a further stage of their recovery process. Therefore, their experiences might not be an accurate reflection of the entire visitors population of Villa Voortman. Second, the results of the study should be generalized with care: the research sample was small (12 actors involved in one setting), and the meeting place is embedded in specific local social, cultural, and health-care related processes that we did not study. Future research is necessary to further elaborate the link between the concept of recovery and meeting places such as Villa Voortman, by means of qualitative research methods focusing on the personal meaning of recovery for persons with dual diagnosis.

\section{Disclosure statement}

The authors report no conflicts of interest. The authors alone are responsible for the content and writing of this article.

\section{Funding}

This work was funded by Bijzonder Onderzoeksfonds (01D33515), [10.13039/501100007229].

\section{References}

Anthony, W.A. (1993). Recovery from mental illness: The guiding vision of the mental health service system in the 1990s. Psychosocial Rehabilitation Journal, 16, 521-538. doi:10.1037/h0095655

Baxter, P., \& Jack, S. (2008). Qualitative case study methodology: Study design and implementation for novice researchers. The Qualitative Report, 13, 544-559.

Broekaert, E. (2009). Naar een integratieve handelingsorthopedagogiek. Antwerpen: Garant.

Broekaert, E., Van Hove, G., D'oosterlinck, F., \& Bayliss, P. (2004). The search for an integrated paradigm of care models for people with handicaps, disabilities and behavioural disorders at the department of orthopedagogy of Ghent University. Education and Training in Developmental Disabilities, 39(3), 206-216.

Broekaert, E., Vandevelde, S., Soyez, V., Yates, R., \& Slater, A. (2006). The third generation of therapeutic communities: The early development of the TC for addictions in Europe. European Addiction Research, 12(1), 1-11. doi:10.1159/000088577

Clarke, V., \& Braun, V. (2014). Thematic analysis encyclopedia of critical psychology (pp. 1947-1952). New York: Springer.
Cruce, G., Öjehagen, A., \& Nordström, M. (2012). Recovery-promoting care as experienced by persons with severe mental illness and substance misuse. International Journal of Mental Health and Addiction, 10, 660-669. doi: 10.1007/s11469-011-9363-0

Davidson, L., Shahar, G., Lawless, M.S., Sells, D., \& Tondora, J. (2006). Play, pleasure, and other positive life events: "Non-specific" factors in recovery from mental illness? Psychiatry, 69, 151-163. doi: 10.1521/ psych.2006.69.2.151

Davidson, L., \& White, W. (2007). The concept of recovery as an organizing principle for integrating mental health and addiction services. The Journal of Behavioral Health Services \& Research, 34, 109-120. doi:10. 1007/s11414-007-9053-7

Drake, R.E., Essock, S.M., Shaner, A., Carey, K.B., Minkoff, K., Kola, L., ... Rickards, L. (2001). Implementing dual diagnosis services for clients with severe mental illness. Psychiatric Services, 52(4), 469-476. doi: 10.1176/appi.ps.52.4.469

Drake, R.E., \& Wallach, M.A. (2000). Dual diagnosis: 15 years of progress. Psychiatric Services, 51(9), 1126-1129. doi: 10.1176/aapi.ps.51.9.1126

Farkas, M. (2007). The vision of recovery today: What it is and what it means for services. World Psychiatry, 6, 4-10.

Flood, A. (2010). Understanding phenomenology: Anne Flood looks at the theory and methods involved in phenomenological research. Nurse Researcher, 17, 7-15. doi:10.7748/nr2010.01.17.2.7.c7457

Gagne, C., White, W., \& Anthony, W.A. (2007). Recovery: A common vision for the fields of mental health and addictions. Psychiatric Rehabilitation Journal, 31, 32. doi:10.2975/31.1.2007.32.37

Harper, D., \& Speed, E. (2012). Uncovering recovery: The resistible rise of recovery and resilience. Studies in Social Justice, 6, 9. doi:10.26522/ssj. v6i1.1066

Horsfall, J., Cleary, M., Hunt, G.E., \& Walter, G. (2009). Psychosocial treatments for people with co-occurring severe mental illnesses and substance use disorders (dual diagnosis): A review of empirical evidence. Harvard Review of Psychiatry, 17, 24-34. doi:10.1080/ 10673220902724599

Khoury, E., \& del Barrio, L.R. (2015). Recovery-oriented mental health practice: A social work perspective. British Journal of Social Work, 45(Suppl.1), i27-i44. doi:10.1093/bjsw/bcv092

Kirmayer, L.J. (2012). Cultural competence and evidence-based practice in mental health: Epistemic communities and the politics of pluralism. Social Science \& Medicine, 75, 249-256. doi:10.1016/j.socscimed.2012. 03.018

Le Boutillier, C., Chevalier, A., Lawrence, V., Leamy, M., Bird, V.J., Macpherson, R., ... Slade, M. (2015). Staff understanding of recoveryorientated mental health practice: a systematic review and narrative synthesis. Implementation Science, 10, 1. doi: 10.1186/s13012015-0275-4

Le Boutillier, C., Slade, M., Lawrence, V., Bird, V.J., Chandler, R., Farkas, M., ... Roberts, G. (2015). Competing priorities: Staff perspectives on supporting recovery. Administration and Policy in Mental Health and Mental Health Services Research, 42, 429-438. doi: 10.1007/s10488-014-0585-x

Leader, D. (2011). What is madness? UK: Penguin.

Leamy, M., Bird, V., Le Boutillier, C., Williams, J., \& Slade, M. (2011). Conceptual framework for personal recovery in mental health: Systematic review and narrative synthesis. The British Journal of Psychiatry, 199, 445-452. doi:10.1192/bjp.bp.110.083733

Murthy, P., \& Chand, P. (2012). Treatment of dual diagnosis disorders. Current Opinion in Psychiatry, 25, 194-200. doi:10.1097/YCO. 0b013e328351a3e0

Ness, O., Borg, M., \& Davidson, L. (2014). Facilitators and barriers in dual recovery: A literature review of first-person perspectives. Advances in Dual Diagnosis, 7, 107-117. doi:10.1108/ADD-02-2014-0007

O'sullivan, T. (2005). Some theoretical propositions on the nature of practice wisdom. Journal of Social Work, 5, 221-242. doi: 10.1177/ 1468017305054977

Pilgrim, D. (2009). Recovery from mental health problems: Scratching the surface without ethnography. Journal of Social Work Practice, 23, 475-487. doi:10.1080/02650530903375033

Price-Robertson, R., Obradovic, A., \& Morgan, B. (2016). Relational recovery: Beyond individualism in the recovery approach. Advances in Mental Health, 15(2), 108-120. doi: 10.1080/18387357.2016.1243014 
Priester, M.A., Browne, T., lachini, A., Clone, S., DeHart, D., \& Seay, K.D. (2016). Treatment access barriers and disparities among individuals with co-occurring mental health and substance use disorders: An integrative literature review. Journal of Substance Abuse Treatment, 61, 47-59. doi:10.1016/j.jsat.2015.09.006

Rapoport, R., \& Rapoport, R. (1957). Community as the doctor. Human Organization, 16, 28-31. doi:10.17730/humo.16.4 ax2701t144885521

Slade, M. (2012). Everyday solutions for everyday problems: How mental health systems can support recovery. Psychiatric Services, 63, 702-704. doi:10.1176/appi.ps.201100521

Slade, M., Amering, M., \& Oades, L. (2008). Recovery: an international perspective. Epidemiologia e Psichiatria Sociale, 17, 128-137. doi:10.1017/ S1121189X00002827

Slade, M., Williams, J., Bird, V., Leamy, M., \& Le Boutillier, C. (2012). Recovery grows up. Journal of Mental Health, 21, 99-103. doi:10.3109/ 09638237.2012.670888

Smith, J.A., Flowers, P., \& Larkin, M. (2009). Interpretative phenomenological analysis: Theory, method and research. London: Sage.

Smith, B.T., Padgett, D.K., Choy-Brown, M., \& Henwood, B.F. (2015). Rebuilding lives and identities: The role of place in recovery among persons with complex needs. Health \& Place, 33, 109-117. doi:10. 1016/j.healthplace.2015.03.002
Stanhope, V., \& Solomon, P. (2008). Getting to the heart of recovery: Methods for studying recovery and their implications for evidencebased practice. British Journal of Social Work, 38, 885-899. doi:10. 1093/bjsw/bcl377

Tew, J., Ramon, S., Slade, M., Bird, V., Melton, J., \& Le Boutillier, C. (2012) Social factors and recovery from mental health difficulties: A review of the evidence. British Journal of Social Work, 42(3), 443-460. doi: 10.1093/bjsw/bcr076

Vandekinderen, C., Roets, G., Roose, R., \& Van Hove, G. (2012). Rediscovering recovery: Reconceptualizing underlying assumptions of citizenship and interrelated notions of care and support. The Scientific World Journal, 2012, 1-7. doi:10.1100/2012/496579

Vandevelde, S., \& Broekaert, E. (2009). A pioneer of milieu therapy: The life and work of Maxwell Jones. Antwerpen: Garant.

Vandevelde, S., De Maeyer, J., De Ruysscher, C., Bryssinck, D., Meesen, D., Vanderstraeten, J., \& Broekaert, E. (2015). Villa Voortman: carte blanche or not? Therapeutic Communities: The International Journal of Therapeutic Communities, 36, 62-73. doi:10.1108/TC-122013-0035

Vanheule, S. (2011). The subject of psychosis: A Lacanian perspective. New York: Palgrave Macmillan.

Zenoni, A. (2009). L'autre pratique clinique: psychanalyse et institution thérapeutique. Toulouse: Erès. 